\title{
L'estructuració interna del consum. La lògica del consum com a lògica de comunicació
}

\section{Vicent Borràs Català}

Universitat Autónoma de Barcelona. Departament de Sociologia

08193 Bellaterra (Barcelona). Spain

Resum

L'article analitza el consum com una práctica de comunicació en el qual les mercaderies perden llur valor d'ús, essent el valor signe el que dóna identitat al bé. A través de l'anàisi de correspondències s'estudia l'estructuració de les dades de consum, el seu vincle i el missatge de que són portadores. (Redaccio)

Paraules clau: consum, comunicacio, signes, símbols, identitat.

Abstract. International structuration of consumption. The logic of consumption as a communication logic

The article analyses consumption as a communication practice by which goods loose their use value and become signs of identity. By correspondence and statistical analysis stuctuzation of data is studied as well as their relationship and significance. (Redaction)

Key words: consumption, communication, signs, symbols, identity.

\section{Sumari}

Introducció Els béns com a suport de

El consum de signes

La possessió, el tenir: un signe en si mateix

Els béns com a comunicadors.

Les dues lògiques la identitat individual i col.lectiva

Les pràcriques, les preferències i els fets, signes d'un mateix missatge

Conclusions

Bibliografia 


\section{Introducció}

Presentar la societat de consum com un moment superior del desenvolupament del capitalisme (Katona, 1968), el que una moderna societat de l'abundància tendeix a pensar en l'existència de la sobirania del consumidor i en una possible eliminació del conflicte social com a conseqüència d'un creixement continuat i progressiu que durà, a llarg termini, a un repartiment del mateix (quant més gros és el pastís més ens en tocarà); no ens serveix per entendre el fenomen del consum.

A final dels anys seixanta i durant els anys setanta, una sèrie de teòrics que alguns autors han denominat sociolegs de la diferenciació (com a principal exponent tenim Baudrillard), entenen el consum com a mitjà que serveix per l'alienació, la integració i sobretor la dominació simbòlica de les masses, per part d'un sistema que fent servir la planificació i el control dels missatges, l'apropiació i generació d'uns codis, juntament amb una creació d'un univers simbòlic de paral.lelisme amb l'univers social.

L'article que aquí presento se situa dins d'aquesta perspectiva teòrica, i més concretament d'aquella que considera el consum com una pràctica de comunicació, en ta qual les mercaderies han perdut, quasi fins a desaparèixer, el seu valor d'ús, on el valor signe dóna identitat al bé. Mostraré que es dóna una estructuració entre els objectes de consum i que les diferents pràctiques conformen un llenguatge, tenint en compte, al mateix temps, que al darrera de la lògica de comunicació es troben lògiques de diferenciació i classificació social. La meva proposta va lligada a fer una prova empírica de l'existència d'estructures internes $i$ articulacions que presenten els fets, els objectes i les pràctiques de consum, i són ells, per si mateixos, els que ens aporten un significat perquè els uns van lligats amb els altres.

Serà mitjançant l'analisi de correspondències que podrem establir una radiografia que ens revelarà l'existència d'una estructuració de les dades i la que ens permetrà veure el lligarn que hi té lloc, com també el missatge del qual són portadores. No és el meu propòsit aquí entrar en una discussió tedrica sobre el possible valor explicatiu global d'aquesta perspectiva, sinó més aviat mostrar que ens ajuda a esbrinar un dels fets de consum contemporanis que segueix sent vàlida per entendre alguns dels aspectes del consum. No hem d'oblidar que allo que caracteritza la societat de consum és la seva complexitat i multidimensionalitat.

\section{El consum de signes}

Entendre el consum passa necessàriament per allunyar-se de la pretensió de trobar un marc naturalista objectiu i general per definir el concepte de necessitat. La noció bàsica de necessitat ha quedat trencada definitivament davant d'un món ple d'objectes, serveis, mercaderies, símbols i imatges, que la moderna societat de consum ha lligat de forma indissoluble al mateix acte de consumirr. La lógica del consum no es pot reduir a una simple lògica de satisfac- 
cions i necessitats, és una lògica de la producció i la manipulació dels significants socials (Baudrillard, 1974).

La producció en les societats capitalistes avançades és una producció per al desig, i els béns no són aquells caracteritzats pel seu valor d'ús. Orti diu al respecte que el consum és una pràctica homogènia en la qual la necessitat s'ha transformat en un desig ${ }^{2}$ el valor d'ús en un fantasma. Cada vegada més el que es consumeix és el símbol dels béns més que el propi bé, realment el mercat d'avui és un mercat dominat pel simbòlic, per l'efímer. El valor signe ve a superar i desplaçar el valor d'ús i el valor de canvi, ja que estan dominats per la lògica de la significació social. La publicitat, com a agent que contribueix a crear i enriquir aquest valor signe, reafirma aquesta mateixa línia subratllant la salut, la bellesa, l'acceptabilitat social i l'exit sexual que resulta de la possessió i l'ús d'un producte determinat.

Hem d'entendre precisament el consum com un procés de significació i comunicació, segons les paraules del propi Baudrillard, que reorganitza el nivell primari de les necessitats a la manera d'una llengua. Els objectes, les mercaderies, els béns, els serveis, fins i tot els mateixos actes de compra s'han convertit en un llenguatge. Però no hem d'oblidar que aquest procés de significació se sirua a sobre d'una realitat marcada per una desigualtat d'accés al consum. Una desigualtat que es fa patent en el propi missatge que donen els objectes i béns i que, a més a més, es legitima i es reprodueix pel sistema productiu. Els objectes no es fabriquen $i$ es difonen per satisfer les necessitats majoritàries, sinó que responen a la seva capacitat de generar un fort efecte de demostració d'estatus (Alonso i Conde, 1994), al qual inevitablement contribueix el valor signe de què són possë̈dors.

Totes les pràctiques de consum no tenen cap sentit si les tractem d'analit* zar com a fets individuals i separats. Si fem el paral.lelisme amb el llenguatge, seria com si tractéssim d'esbrinar el significat que tenen els noms, els verbs, els adjectius, etc. de manera deslligada i separada. No hem d'entendre el consum com un deler de possessió d'objectes, sinó més aviat com tota una organització de la substància significant que transforma la cosa en un signe, des d'on el consum passa a ser una activitat sistemàtica de manipulació de signes (Marafioti, 1988). Nosaltres juguem i manipulem els signes, acumulem, canviem i distribuïm els objectes; utilitzem uns serveis o uns altres, prescindim d'unes mercaderies $\mathrm{i}$ invertim en unes altres segons el missatge que volem donar. Podem dir que no és casual que qui disposa de microones també disposi de rentaplats, ni que qui tingui més de 500 ldibres a casa, sigui lector regular de diaris. No s'entén que una senyora que porta un abric de visó i va a una sessió d'opera al Liceu s'hi desplaci amb metro, sinó que ho farà amb taxi. No

1. No és el nostre objecte entrar en la discussió sobre el concepte de necessitat. Vegeu L.E. Alonso "La producción social de la necesidad". Economistas, 18, p. 26-31.

2. Respecte al desig, Galbraight diu que no se'ns obliga a comprar un nou model d'automò. bil, ni un nou laxant, arribem a creure que hem de comprar-lo. Els desitjos han estat buidats de contingut per l'abundància i després són manipulats, tracten que les persones desitgem el que el sistema subministra (J.K. Galbraith, 1984). 
són, per tant, els objectes com a tals els que es consumeixen, sinó els signes dels quals ells són portadors. La lògica del consum és una lógica de manipulació de signes i no pot ser reduïda a la funcionalitat dels objectes. Consumir significa, entre altres coses, intercanviar significats socials i culturals $\mathrm{i}$, de fet, els bérs són el mitjà d'intercanvi (Leonini, 1982).

No tots els autors o estudiosos del consum estan totalment d'acord amb aquesta perspectiva teòrica per la qual considerem el consum com una pràctica fonamentalment comunicadora. L'autor Grant McCracken considera que la metàfora que els objectes inanimats son un llenguatge o funcionen com un llenguatge és enganyosa. Realitza un estudi en què tracta de veure les semblances i diferències entre la llengua i el món de la roba. Per a ell el món de la indumentària considerat com un llenguatge presenta una sèrie de limitacions o més aviat no acompleix tot un seguit d'aspectes:

- No hi ha una evidència de la lectura lineal discursiva sobre la roba o que sobre la roba fan els individus.

- Els significats de la roba estan subjectes a un nombre limitat de vocabulari, adjectius i noms.

- Les diferents combinacions de roba de vegades converteixen el missatge en un trencaclosques, del qual s'han de treure algunes peces per poder-lo resoldre.

El propi McCracken proposa una sèrie de solucions al problema apuntant que el món de la roba pot respondre a un sistema especial de codi, malgrat que considerar que aquest sigui un codi i no pas un llenguatge pot implicar menys èxit com a sistema comunicatiu. També afirma que si ho entenem aixú, els codis i en el seu cas els vestits són missatges en si mateixos i no parts d'un missatge. Però també ens diu que la cultura material tan sols ens permet la representació d'un nombre limitat de coses en un nombre limitat de possibilitats. A més, una altra de les grans limitacions és que aquest significat es troba en un trànsit constant, és un flux constant, cap i des del món social, ajudat per l'esforç individual i col-lectiu de productors, publicistes i consumidors (McCracken, 1988). Més que una limitació es pot dir que es tracta d'una riquesa, ja que el valor signe dels objectes ha d'estar contextualitzat $i$, igual que la llengua, el que al segle passat significava una cosa avui en pot significar una de diferent ${ }^{3}$. És la doble vessant que tenen els béns, els serveis, les mercaderies de consum com a valors simbolics que representen i com a comunicadors, la qual cosa fa que aquests passin de moda i arribi un moment en què ja no serveixin per expressar el que ens expressaven, és a dir, que el seu valor signe canvii (Leonini, 1982).

3. Contrariant aquesta idea i sobre el mateix tema, la roba o més aviat el món de la moda, $A$. Lurie fa un interessant assaig sobre la indumentària com un llenguarge que ens serveix per identificar-nos a nosaltres $\mathrm{i}$ identificar els altres. Vegeu A. Lurie. El lenguaje de la moda. Barcelona: Paidos Contextos, 1994. 
El meu proposit aquí és tractar de mostrar que els objectes, les mercaderies, els serveis $\mathrm{i}$ els hàbits de consum presenten una estructura, tenen una estructuració interna que és la que ve donada per la seva pròpia naturalesa comunicativa, els uns van lligats amb els altres i és aquest lligam el que ens proporciona coherència. Una cohetència que no és ni eterna ni ubiqua i que necessàriament ha d'estar vinculada a les categories culturals de la societat on ens trobem o ens situem; entenent per categories culturals aquells aspectes històrics, socials i econòmics que configuren les particularitats d'una societat.

És la correspondència entre les categories culturals i els béns de consum la que ens ajuda a esbrinar quins béns van units i quins no. Es necessari lligar els diferents actes de consum, com també és necessari que es donin significats equivalents perquè el missatge sigui descodificat pels receptors, per exemple, el fet que observem en un individu que condueix un BMW i dugui també un rellotge Rolex ens dóna una idea més chara sobre ell. És la relació que estableixen amb els altres signes el que forma o estructura el sistema de significació social. Per tant, direm que un bé és un comunicador més bo quan es troba envoltat d'un seguit de béns que comporten el mateix significat. Un bé no és un bon comunicador si existeix de forma aillada o en grups heterogenis. Qualsevol bé, dins del món del consum, estarà lligat a un conjunt d'altres fets, objectes, serveis, que reafirmen el mateix significat i missatge, aportant significats equivalents o/i complementaris. La consistència d'aquests béns es troba reafirmada per la seva natura, el seu origen i el seu propi significat cultural.

\section{La possessió, el tenir: un signe en si mateix}

Malgrat que, com diu Baudrillard, la discriminació ha passat avui, amb l'elevació del nivell de vida, de la possessió pura i simple a l'organització i el coneixement operatiu dels objectes, segueix tenint importància la possessió com a valor distintiu entre els individus.

Des del principi dels temps el fet de posseir enfront del de no posseir ha estat una font de desigualtat. Ja Marx va establir la seva visió de l'estructura social a partir de dos grups socials que estaven diferenciats per la possessió/no possessió dels mitjans de producció. Avui en dia les formes de possessio s'han tornat més sofisticades, disposar d'informacio, disposar d'una bona formació, disposar d'una xarxa de relacions àmplia $\mathrm{i}$ important (important per la posició social que ocupen els individus que hi estan inserits) pot, a més de legitimar les diferències materials, consolidar-les i reproduir-les.

Donada l'abundància aparent (i dic aparent perquè és una abundància que es veu en les grans superficies, però no vol dir que es doni en totes les llars) en què viuen les societats avançades i la proliferació d'objectes i béns que al llarg dels anys es troben més barats i, per tant, amb més possibilitats de ser consumits per les masses; la possessió de béns materials encara segueix sent un símbol d'estatus i posseir-los forma part d'una simbologia. 


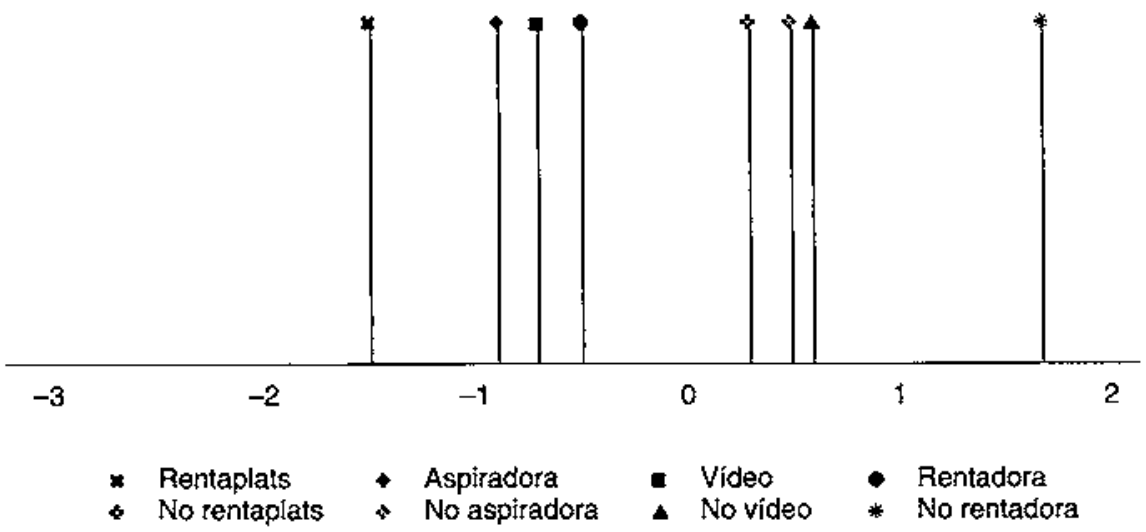

Figura 1. Béns duradors. Primer eix, andilisi de correspondències. $89 \%$ de variança explicada.

Si a més a més tenim en compte que ens trobem en la societat espanyola fortament marcada pel fet de tenir i no pel fet de ser, com molt bé explica Conde ${ }^{4}$ en assenyalar la propietat, en definitiva, el posseir com un dels valors característics de la burgesia espanyola (i que no és arriscat afirmar que també ho ha estat en la vella burgesia catalana $a^{5}$ a a llarg de la història, veiem que la possessio ha marcat i segueix marcant els consumidors de la nostra societat.

La figura 1 mostra l'eix que obtenim en aplicar l'anàlisi de correspondències sobre un conjunt de variables referides a la possessió de béns duradors a la llar. En la banda dreta del gràfic tenim els que no posseeixen rentaplats, ni aspiradora, ni video, marquen el punt extrem els que ni tan sols posseeixen rentadora. En la banda esquerra tenim els que posseeixen, marcant la tendència màxima, els que fins i tor tenen rentaplats ${ }^{6}$.

Si en fem una interpretació, tenim que la possessió/no possessió és la que marca aquesta dimensió, i és el lígam que presenten els objectes en si, pel fet de posseir-los, com a signes d'un llenguatge, la qual cosa confereix un sentit $i$ una logica als seus consumidors del mateixos. Tant per a ells com a individus

4. Vegeu F. Conde. Genesis y desarrollo de la sociedad de consumo en España. Madrid: IV Congreso Español de Sociología, I992.

5. La publicitar recull molt bé aquests valors; tan sols hem de veure dos dels últims anuncis a TV3. Un és de l'embotit Tarradelles, en el qual un avi fa al seu nét, un repàs de tores les propietats que té al mateix temps que unca un pa amb tomàquet, $i$ acaba l'anunci dient que algun díia tot serà del nét ('?hereu). L'altte anunci és sobre el suplement de La Vanguardia i s'hi mostra tota una sèrie de meravelles arquitecròniques dient que el senyor de la imatge n'és el propietari.

6. Les dades sobre les quals s'ha realitzat aquesta anàlisi provenen de l'Enquesta de la Regió Merropolizana de Barcelona, 1990. 
que s'identifiquen com els que posseeixen com per a la resta que els classifica en el grup dels que tenen.

\section{Els béns com a comunicadors. Les dues lògiques}

La gran majoria de les recerques realitzades que tracten d'estudiar l'home i les seves formes de vida al llarg de la història han utilitzat els béns, els objectes, les seves obres (construccions arquitectòniques, pintures, vestits, ceràmiques, etc.) com a mitjans que ens informen sobre els seus costums, la seva organització, la seva forma de viure i fins i tot els seus valors, els seus símbols i les seves creences. L'antropologia i la història han fet servir com a suport de les seves investigacions, els béns i els objectes, com a testimonis, com a informadors culturals.

Dins la sociologia no és tan comú fer servir els béns i els objectes com a font d'informació, malgrat que no és una pràctica habitual, autors com Elias ${ }^{7}$ ha fet un estudi excel.lent sobre la vida de la societat cortesana a través de la distribució $\mathrm{i}$ les formes dels habitatges de l'aristocràcia i la noblesa; arribant a descobrir quina era la forma de vida d'aquests estaments, quina era la seva funció i com eren els seus habitatges, com estaven distribuides les diferents estances, eren vehicles comunicadors i alhora legitimadors del paper social dels seus propietaris. Els béns són utilitzats per les diferents ciències humanes com la part visible de la cultura que volen estudiar. Aquest fet comporta reconèixer una doble vessant dels objectes o béns: que siguin al mateix temps resultat $\mathrm{i}$ contribució de la cultura. Per tant, direm que els béns són sobre totes les coses signes culturals.

Si tenim en compte que el mercat és la forma de desenvolupament capitalista actual i la forma dominant de la cultura, no ens serà arriscat afirmar qute són les mercaderies justament les que organitzen el sistema de comunicació social. És en la seva funció comunicadora, en la seva funció d'intercanvi, en què s'expressen els valors $i$ en què es veuen les diferències i en què actuen com a suport.

Podem parlar del consum, per tant, com a fenomen social que comprèn dues logiques, dues lògiques que van unides i que sense entendre l'una no podem entendre l'altra. Per una banda, tenim la lògica de la comunicació, Iligada inseparablement al valor signe que presenten o que tenen tots els objectes, béns, serveis $\mathrm{i}$ actes de consum, en definitiva, les pràctiques de consum que s'inscriuen en un codi que les dota de sentit. Per altra banda, tenim la logica de la diferenciació, diferenciació que ve al mateix temps ligada al valor signe que té cada objecte, bé, mercaderia (que són diferents entre si per la seva mateixa funció comunicadora), diferenciació que ve donada pel fet que les mercaderies impliquen valors, valors fonamentals d'estatus jeràrquic.

Aquesta lògica de la diferenciació és la que ens ajuda a entendre que avui no hi ha consum perques es doni la necessitat objectiva de consumir, hi ha pro- 
ducció social d'un material de diferències, d'un codi de signiffcacions i de valors d'estatus, a sobre del qual se situen els béns, els objectes i les pràctiques de consum $^{8}$. I és la capacitat comunicadora que tenen els béns la que ajuda a esbrinar aquesta diferenciació social.

\section{Els béns com a suport de la identitat individual i col-lectiva}

La persona necessita béns per poder comunicar-se amb els altres i per donar sentit al que està succeint al voltant seu (Douglas i Isherwood, 1979). Sense els béns de consum, certs actes de definició d’un mateix i la definició col.lectiva en aquesta cultura serien impossibles. S'ha arribat a una sofisticació tal que no són, tan sols, els productes (per la seva diferència intrínseca entre ells), sinó els signes que porten aquests. La marca d'un producte no marca ja el producte, marca el consumidor com a membre del grup de consumidors de la marca. La identitat social ve donada o està en funció dels productes i les marques que consumim, quan comprem la mercaderia comprem bàsicament els signes que ens donen la identitat (J. Ibánez, 1994). Si tan sols donem un cop d'uli a una part dels productes, com pot ser els que formen part del món de la roba, podem afirmar que molt abans que jo mapropi a vostè pel carrer, suficientment perquè puguem parlar, vostè ja m'està comunicant el seu sexe, la seva edat i la classe social a què pertany per mitjà d'allo que porta (Lurie, 1994).

Al meu parer, no és arriscat extrapolar aquesta idea d'identificació individual $i$ alhora de grup de la qual ens servim els individus, tant pel que fa a la roba com a altres aspectes que configuren la nostra quotidianitat: la pràctica d'esport (si en practiquen o no, el tipus d'esport, la despesa que implica, etc.), el nombre de preferències musicals que tenim, l'assistència a espectacles, etc. Els objectes constitueixen un element fonamental en la creació i el manteniment de la identitat, són elements essencials en el procés d'interacció entre els individus. A través d'ells constrüm el personatge que volem semblar, que volem ser i en la interacció transmetem informació sobre els nostres valors, sobre la nostra posició social (Leonini, 1982).

Parlar d'identitats individuals a través dels objectes de consum no ens ha de fer pensar que els individus, les seves intencions tal com són manifestades per ells mateixos $i$ les seves accions són les que expliquen el comportament enfront del consum ${ }^{9}$. Al meu parer, les identificacions individuals a través dels objectes de consum són identitats de grup, es desitja ser del grup i per al grup,

8. N'hi ha prou de renir present que els béns es converteixen en signes distintius -que poden ser uns signes de distinció, però també de vulgarirat, des del moment en què són percebuts relacionalment- per veure que la representacio que els individus i els grups posen inevirablement de manifest, mitjançant les seves pràctiques i les seves propietats, forma part integrant de la realitat social (Bourdieu, 199I).

9. Per aprofundir més sobre el tema vegetu L.E. Alonso; J. Callejo. Consumo e individualismo metodoldgico: una perspectiva critica. Madrid: IV Congreso Español de Sociologfa. 1992. 
hem de pensar, tal com diu Ibáfíez, que l'estructura de la societat de consum és de grup.

Per a Bourdieu aquesta identificació ha de presentar una coherència, però no pas una coherència natural, sinó una que ve donada per una unitat de gust. El gust com a propensió i aptitud per a l'apropiació (material i/o simbòlica) d'una classe determinada d'objectes o de pràctiques propies d'una classe i que situen en una classe. El consum comporta judicis discriminatoris, els quals al mateix temps identifiquen i mostren el nostre judici particular del gust respecte al gust dels altres.

No hem de pensar que aquest concepte del gust és un element estàtic, és un aspecte que canvia al llarg del temps. No va ser fins que van apareixer les fabriques com a forma majoritària d'ocupació per a les classes populars que el color moreno (el bronzejat) de la pell va adquirir un altre significat: fins al segle XIX estar moreno sobretot per les dones: era poc estètic o de mal gust, significava o denotava poc estatus. Quant, la majoria de les classes treballadores es passaven les jornades excessivament llargues lluny de la llum del sol, es va produir un canvi en la concepció estètica de la bellesa, ser o estar bronzejat ha esdevingut un signe de bellesa, de salut, de benestar. Fins i tot als darrers anys temim els raigs UVA com a substitut del sol per als mesos en què la climatologia no acompanya.

Per tant, segons Bourdieu és el que ell anomena gust el que ajunta les persones i les coses que van bé juntes, que conviuen mútuament. Lluny d'entrar en la identificació social dels individus que tenen unes pràctiques de consum similars, mostraré que hi ha fets, hàbits i preferències qute van juntament amb altres i que aquests es presenten estructurats, malgrat la seva propia heterogeneïtat, com a elements d'àmbits diferents.

\section{Les pràctiques, les preferències i els fets, signes d'un mateix missatge}

La societat de consum, com a forma cultural dominant, estableix els mecanismes en què els hàbits, les activitats i fins i tot les preferències es tradueixen en stmbols d'allò que volem comunicar. La funció que tenen els objectes en la creació i el manteniment de la identitat no és exclusiva d'ells mateixos, les pràctiques que els individus realitzem, els fets i els nostres hàbits en la seva dimensió de consum a la qual pràcticament estem lligats ${ }^{10}$, també ens serveixen com a vincle d'identitat, i per tant, presentaran una estructuració, un lligam intern.

A continuació es presenta un eix que resulta de l'anàlisi de correspondències aplicat a variables referides $a$ : les preferències musicals, les pràctiques d'esport i l'assistència a espectacles. En la banda dreta del gràfic tenim els que van a más de dos espectacles al mes, tenen més de dues preferències musicals i

10. Quasi la totalitat d'activitats que realitzem en el nostte temps tenen o impliquen un tipus o un alrre de consum, practicar algun esport va ligat almenys a un tipus determinat d'indumentària o fins i tot al fet d'estar inscrit a un gimnàs. 


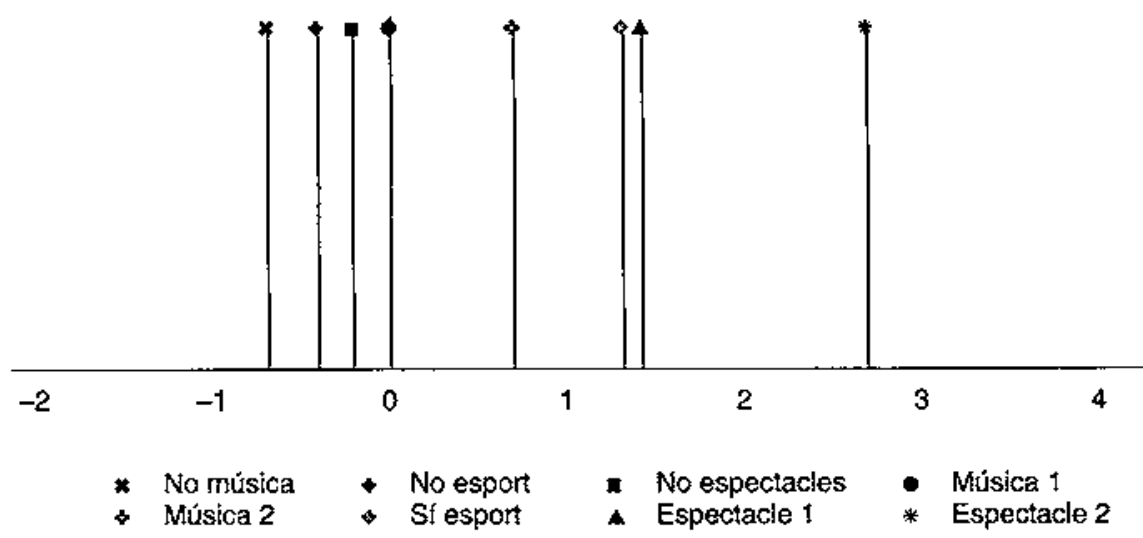

Figura 2. OCI: fets, pràctiques, preferències. Primer eix, andalisi de correspondències. $89 \%$ de variança explicada.

practiquen esport. En la banda esquerra tenim els que no tenen cap preferència musical, no practiquen cap esport i no van a cap espectacle (vegeu la figura 2) ${ }^{11}$. Aquí veiem com el fet d'assistir a espectacles, tenir preferències musicals i practicar esports, fets que poden, a primer cop d'ull, ser deslligats, presenten una estructuració interna, per una banda, donada per la seva funció comunicadora de la identitat personal i, per l'altra, com a elements que marquen una diferenciació social.

\section{Conclusions}

Lluny d'entrar en el debat de la validesa total del denominat pansemiologisme (èmfasi principal en la dimensió comunicadora de la praxi del consum), com a plantejament teòric explicatiu de la realitat del consum, aquest article tracta d'aportar evidència empírica que allò que caracteritza el fet de consumit, ja sigui si ens referim als objectes com si ens referim als diferents fets $i$ pràctiques, presenten una estructuració $i$ una arriculació interna. Aquesta ve determinada per la mateixa naturalesa comunicativa, que és la que dóna la coherència interna $i$ la que ens pot ajudar a trobar nous conceptes que ens ajuden a esbrinar més clarament la realitat multidimensional del consum.

11. Les dades sobre les quals s'ha realitzat aquesta anàlisi provenen de l'Enquesta de la Regí Metropolitana de Barcelona, 1990. 


\section{Bibliografia}

AlONSO, Luis Enrique (1985), "Los orígenes del consumo de masas: el significado de una transformación histórica». Estudios sobre consumo, 6, p. 11-19.

- (1986). "La producción social de la necesidad". Economistas, 18, p. 26-31.

ALONSO, Luis Enrique; CALLEJO, Javier (1992). Consumo e individualismo metodologico: una perspectiva critica. Madrid: IV Congreso Español de Sociología.

ANDRES ORIZO, Francisco; SANCHEZ FERNANDEZ, Alejandro (199I). El sistema de valors dels catalans. Barcelona: Institut Catal d'Estudis Mediterranis.

BAUDRILlARD, Jean (1969). El sistema de los objetos. Madrid: Siglo XXI.

- (1970). La Société de Consommation. París: Le Point de la Question.

- (1976). La genesis ideolbgica de las necesidades. Barcelona: Editorial Anagrama.

- (1987). Critica de la economía política del signo. Madrid: Siglo XXI.

Bourdieu, Pierre (1971), "Le Marché des Bienes Symboliques». L'Anée Sociologique, 22, p. 49-126.

- (1974). "Les fractions de la classe dominanter er les modes d'appropriation de l'oeuvre d'art.. Information sur les Sciencies Sociales, 13, 3, p. 7-31.

- (1978). «Sport and social class". International Social Sciencie Council, I7, 6, p. 819-840.

- (1988). La distincion. Criterio y bases sociales del gusto. Altea: Taurus Humanidades.

Castillo Casthllo, José (1987). Sociedad de consumo a la española. Madrid: Eudema actualidad.

CONDE, Fernando (1992). Génesis y desarrollo de la sociedad de consumo en España. Madrid: IV Congreso Español de Sociología.

CORNEjo, J.M. (1988). Técnicas de investigación social: El análisis de correspondencias (teorla y práctica). Barcelona: PPU.

DOUGLAS, Mary; ISHERWOOD, Baton (1979). The world of goods. Nova York: Basic books, inc., Publishers.

Elias, Norbert (1982). La sociedad cortesana. Mèxic: Fondo de Cultura Económica.

GalBRAITH, John Kenneth (1984). El nuevo Estado industrial. Madrid: Sarpe.

- (1992). La Cultura de la Satisfacción. Barcelona: Ariel.

- (1992). La sociedad opulenta. Barcelona: Ariel.

GaRNHAM, Nicholas (1986). "Extended review: Bourdieu's Distinction». Sociological Review, 34, 2, p. 423-433.

GIMENo, Juan A. (1982). "La evolución del consumo en España». Documentación social, vol. 48 , p. $105-131$.

Ibañez, Jesús (1979). Más allá de la sociologia. El grupo de discusión: Técnica y critica. Madrid: Siglo XXI.

- (1987). "Una publicidad que se anuncia a sí misma». Telos, 8, p. 117-123.

- (1994). Por una sociologta de la vida cotidiana. Madrid: Siglo XXI.

KaTONA, G. (1968). La sociedad de consumo de masas. Madrid: Rialp.

LEONINI, Luișa (1982). "I Consumi: Desideri, Simboli, Sostegni». Rassegna Italiana di Sociologia, 23, 2, p. 251-269.

- (1990-91). "A che servono le cose? A proposito di due contributi sui consumin. Quaderni di Sociologia, 29, p. 168-178.

LUCAS, A. DE (1988). «Publicidad e ideología». Cuadernos Contrapunto, p. 21-27.

- (1990). "Fantasmática de la publicidad". Cuadernos Contrapunto, p. 64-76.

LURIE, Alison (1994). El lenguaje de la moda. Una interpretación de las formas de vestir. Barcelona: Paidos. Contextos. 
MaluQuer de MOTES, J. (1985). "La revolución industrial en Cataluña». A SANCHEZALBORNoz, N. La modernización social en España 1830-1930. Madrid: Alianza Universidad.

MARAFIOTI, R (1988). Los significantes del consumo. Semiologia, medios masivos y publicidad. Buenos Aires: Biblos.

Marinas, José Miguel; Santamarina, Cristina (1992). Historia y proceso de la investigación de mercados: comunicación y consumo en España. Madrid: IV Congreso Español de Sociología.

MCCRACKEN, Grant (1988). Culture and consumption. Bloomington: Indiana University Press.

McNALl, Scott G. (1990). "You are what you eat: some thoughts on consumption and marxist class theory". Mid-American Review of Sociology, 14, 1-2, p. 45-52.

Migutlez, F.; SOlE, C. (1987). Classes socials i poder politic a Catalunya. Barcelona: PPU.

MiGUELEZ, F.; TORNS, T. (1992). Treball, condicions econòmiques i formes de consum. Enquesta de la Regio Metropolitana de Barcelona, 1990. Volum 2. Barcelona: Institut d'Estudis Metropolitans de Barcelona.

ORTI, A. (1970). "Las bases sociales de la modernización policica». A MARTINEZ CuAdRADO, M. Cambio social y modernización politica. Madrid: EDICUSA.

Subirats, Marina; SANCHEZ, Cristina; DOMINGUEZ, Màrius (1992). Grups i classes socials a La Regió Metropolitana de Barcelona. Enquesta de la Regio Metropolitana de Barcelona, 1990. Volum 5. Barcelona: Institut d'Fsudis Metropolitans de Barcelona.

Veblen, T. (1944). Teorta de la clase ociosa. Mèxic: Fondo de Cultura Económica. 